CAmerican Psychological Association, 2021. This paper is not the copy of record and may not exactly replicate the authoritative document published in the APA journal. The final article is available, upon publication, at: https://doi.org/10.1037/cou0000594

\title{
Other- (vs. Self-) Oriented Meaning Interventions Enhance Momentary Work Engagement Through Changes in Work Meaningfulness
}

\author{
Katarzyna Cantarero, ${ }^{1}$ Wijnand A.P. van Tilburg, ${ }^{2}$ and Ewelina Smoktunowicz ${ }^{3}$ \\ ${ }^{1}$ Social Behavior Research Center, \\ Faculty of Psychology in Wroclaw, SWPS University Wroclaw, Poland \\ ${ }^{2}$ Department of Psychology, University of Essex, Colchester, United Kingdom \\ ${ }^{3}$ Faculty of Psychology, StressLab: Stress Research Center, SWPS University, Warsaw, \\ Poland
}

\begin{abstract}
Author Note
Please address correspondence to Katarzyna Cantarero, SWPS University of Social Sciences and Humanities, Faculty of Psychology in Wroclaw, ul. Ostrowskiego 30b, 53-238 Wroclaw, Poland, Tel. + 48071 7507260. Email: kcantarero@swps.edu.pl

Author contribution: Katarzyna Cantarero, Wijnand A.P. van Tilburg \& Ewelina Smoktunowicz have designed the studies. Katarzyna Cantarero has conducted the studies and the analysis. Katarzyna Cantarero, Wijnand A.P. van Tilburg \& Ewelina Smoktunowicz have contributed to the writing of the manuscript and agreed on its final version.

Acknowledgements

Study 1 was conducted with support of a research grant awarded by the National Science Center in Poland to Katarzyna Cantarero 2018/31/D/HS6/03329. Study 2 and Study S1 were conducted thanks to a post-doctoral scholarship within the Bekker Programme awarded by the National Agency of Academic Exchange in Poland to Katarzyna Cantarero PPN/BEK/2019/1/00324/U/00001.
\end{abstract}




\begin{abstract}
We tested whether a short, online meaning intervention boosts momentary work engagement through an increase in perceived work meaningfulness. In Study $1(N=227)$ employees who were asked to write why their work was meaningful subsequently experienced higher work meaningfulness and higher momentary work engagement (MWE) compared to a control group. Work meaningfulness mediated the relationship between the intervention and MWE. Study 2, conducted among employees $(N=254)$, found that writing about how one's work serves a greater good (vs. how it advances personal career, vs. control) led to an increase in work meaningfulness, which consequently predicted MWE. The research examines a new tool to enhance work meaningfulness that can be easily and widely applied and that provides insight into how sources of meaningful work are related to work meaningfulness and to important occupational outcomes.
\end{abstract}

Keywords: meaning interventions, work meaningfulness, work engagement, self vs. other

\title{
Public Significance Statement
}

This research examines a short, online and inexpensive tool that can boost work meaningfulness and, consequently, momentary work engagement. Employees that focused on the meaning of their work not only experienced higher levels of work meaningfulness, but also higher momentary work engagement. When employees were asked to focus and write down how their work served a greater good, it elevated work meaningfulness as compared to focusing on how one's work allowed them to advance their personal career. This suggests that only other-oriented and not self-oriented sources of meaning can help to bolster momentary work engagement through changes in work meaningfulness. 


\section{Other- (vs. Self-) Oriented Meaning Interventions Enhance Momentary Work Engagement Through Changes in Work Meaningfulness}

Meaningful work ${ }^{1}$ is often described as work that is seen as significant and worthwhile by the person performing it (Lysova et al., 2019); it is an essential ingredient for human flourishing. Perceiving work as meaningful is associated with positive personal outcomes, such as self-image, well-being, and lower levels of anxiety (see Steger, 2017, for an overview). Work meaningfulness has also work-related benefits such as predicting elevated work engagement (May et al., 2004).

Work engagement is defined as "a positive, fulfilling, work-related state of mind that is characterized by vigor, dedication, and absorption" (Schaufeli et al, 2002, p. 74). It has become an extensively researched concept in the context of positive occupational psychology (Schaufeli et al., 2019). It was found to have numerous implications that are beneficial for employees and organizations, including personal initiative, organizational commitment, and better performance (Schaufeli \& Bakker, 2014). Work engagement has been linked to more satisfied employees, better task-performance, and financial gains (Bakker \& Albrecht, 2018). In fact, its benefits can extend even beyond the workplace. For example, Hakanen and Schaufeli (2012) found that work engagement predicted, over a period of several years, higher life satisfaction and lower depressive symptoms. Accordingly, this variable, and understanding how to enhance it, is of great relevance to both well-being at work-related and beyond. Importantly, work engagement can be treated at a state level (Breevaart et al., 2012), and can be enhanced within a short period of time (Sonnentag et al., 2010).

\footnotetext{
${ }^{1}$ We use the terms "meaningful work" and "work meaningfulness" interchangeably.
} 
Work meaningfulness has been lauded as one tentative contributor to work engagement (e.g., May et al., 2004). It fosters, aside from work engagement, personal growth and motivation at work, prevents job alienation, and remedies feelings of disengagement. As a case in point, Lavy and Naama-Ghanayim (2020) found that the more teachers perceived their work to be meaningful, the more their students (aged 12-16) felt cared for by their teacher. A meaningful job allows the person to flourish and contribute beyond the call of duty to contribute. In fact, Stein and colleagues (2019) have suggested that "meaningfulness is one of the most sought-after work features." (p. 685), thus placing work meaningfulness in a position of importance and, accordingly, a phenomenon of particular significance for the individual and society.

Similarly to work engagement, meaningful work was found to increase as a result of contextual factors (Allan et al., 2018). This suggests that work meaningfulness and work engagement may be effectively improved by situational interventions (e.g., Fletcher \& Schofield, 2019). One of the influential perspectives on the formal aspects of the jobs is the job characteristics model, (JCM) (Hackman \& Oldman, 1976) which showcases five such features namely, task identity, task significance, skill variety, autonomy, and feedback. Task significance, defined as an extent "to which the job has a substantial impact on the lives or work of other people" (Hackman \& Oldham, 1976; p. 257), has been subsequently found in a meta-analysis to have the strongest association with experienced meaningfulness (Humphrey et al., 2007). Additionally, the same work showed that meaningfulness was further associated with positive work outcomes such as job satisfaction, and studies that built on these results found that the same was true for other outcomes such as employee engagement (Landells \& Albrecht, 2019). Taken together, these theoretical framework and empirical findings indicate that performing an activity on the job that impacts other people can increase people's sense of meaningful work, and subsequently increase work engagement. Our goal was to examine the 
effectiveness of the intervention aimed at increasing work engagement by situationally altering work meaningfulness.

Research by Allan et al., (2014) found that nearly $30 \%$ of people do not perceive their work as meaningful. Relying on content analysis, the authors found that the majority of those who did report their work as being meaningful did so because they felt that their work was helping others. Aside from this major source of work meaningfulness, these authors found that other common categories were that meaningful work involved serving a greater good, personal growth and enjoyment, generating or preserving knowledge and making money (Allan et al., 2014). Their study thus suggested several perceived sources of meaningful work.

We further postulate that the specific sources of work meaningfulness can be helpfully placed into two major categories: those directed at benefiting oneself (self-oriented sources of meaningful work), and those directed at benefiting others (other-oriented sources of meaningful work). This proposition draws also from Rosso and colleagues (2010) who argued that the distinction between self vs other is useful in analyzing sources of meaningful work. It has been demonstrated that helping others effectively increases perceived work meaningfulness (Allan et al., 2018). Interestingly, no studies have experimentally examined whether focusing on different sources of meaningful work causally increases work meaningfulness, and, subsequently, crucial occupational outcomes such as work engagement. Identifying these paths would extend previous findings on work engagement and show how different types of sources of meaningful work may contribute to work engagement.

The aim of this research was twofold. First, we set out to examine if it is possible to introduce a convenient tool to boost work engagement through work meaningfulness. An increasingly popular mode of providing psychological interventions is through new technologies; some internet interventions have been found to be effective, easily accessible and scalable (Andersson, 2018). Therefore, we tested if a short, online writing intervention 
can boost work meaningfulness and momentary work engagement. Additionally, we set out to test if the source of meaningful work matters when it comes to interventions aimed at increasing work meaningfulness and momentary work engagement. We designed and tested whether an intervention that sought to emphasize either other-benefitting or self-benefitting aspects of work contributed to work engagement through elevated work meaningfulness. We also hypothesized that other-oriented and self-oriented meaning interventions increase perceived work meaningfulness compared to control condition. We hypothesized that work meaningfulness predicts momentary work engagement and that meaning interventions increase momentary work engagement. In addition, we hypothesized that work meaningfulness mediates the relationship between meaning interventions and momentary work engagement.

\section{Method}

\section{Study 1}

We tested in Study 1 if an intervention aimed at elevating perceived work meaningfulness enhanced momentary work engagement. We examined if this intervention enhanced momentary work engagement through changes in work meaningfulness. Data linked to the research presented in the manuscript is available at: https://osf.io/5vfny/?view_only=e6e752c1b2534b1fa28462397712c352. The study was approved by the Ethics Committee at the first author's university (Approval number 06/P/12/2018).

\section{Participants and Design}

Sample size was determined assuming effect size $=.08,(\alpha=.05)$ with a power of $(1-$ $\beta)=.95$; we aimed for at least 219 participants. Two hundred and twenty-seven MTurk workers that were then employed or were business owners (92 women, 133 men, 1 other, 1 undisclosed; age ranged from 21 to $68\left(M_{\text {age }}=39.42 S D_{\text {age }}=10.30\right)$ took part in this online 
study in exchange for $0.70 \$)$. Three per cent of participants had up to one year of working experience, $18 \%$ worked between 1 and 5 years, $16 \%$ between $5-10$ years and $63 \%$ worked more than 10 years in total. Seven per cent of participants terminated their education at high school or earlier, $22 \%$ had some college or an associate degree, $42 \%$ had a Bachelor's degree and 29\% had at least a Master's degree. No cases were deleted. These participants were randomly assigned to one of two conditions (meaning intervention vs. control) of a betweensubjects design.

\section{Procedure and Materials}

Participants were randomly assigned to either the intervention or the control condition. In the meaningful condition participants read: "Even if it might be difficult for you, please write why your work is meaningful. Think for a moment about this, and then write down three keywords that capture how your work is meaningful. Now explain, in detail, why your work is meaningful. Try to write at least three sentences about how your work is meaningful.” In the control condition instead of asking about work meaningfulness, we asked participants to describe what equipment they use at work. We opted for this intervention procedure given that past studies have had considerable success in using similar writing tasks to enhance a range of other positive psychology qualities (e.g., Davis et al., 2016), including sense of autonomy, competence, and relatedness (Cantarero et al., 2021), and, in occupational context, gratitude at work (Adair et al., 2020). Furthermore, the inexpensive and simple nature of such tasks make them potentially powerful tools to aid well-being. Recent multi-lab study shows that simple reappraisal interventions can effectively boost positive emotions (Wang et al., 2021).

Participants then indicated whether they searched for meaning in their job: "I have searched for meaning in my job activities"; "I have wondered about the purpose of my work", "I have thought about what the meaning of my work is" $(\alpha=.78)$ and how meaningful their 
work is: "The work I do is very important to me"; "My job activities are personally meaningful to me" and "The work I do is meaningful to me" ( $\alpha=.96$, Spreitzer, 1995). The answers were given with a response scale ranging from 1 (Strongly disagree), to $5=($ Strongly agree).

Next, participants completed a scale that measured momentary work engagement. They filled-in the three-item Momentary Work Engagement Scale that we adapted to reflect their current state as we asked about their experience at the time: "The following statements are about how you feel at work today. Please read each statement carefully and decide if you feel this way about your job today. If you don't have this feeling, mark the ' 0 ' (zero) in the space after the statement. If you have this feeling, indicate how strongly you feel it by marking the number (from 1 to 6$)$ that best describes how much you feel that way." $(\alpha=.89$, "Today, I feel bursting with energy at my job"; "Today, my job inspires me"; "Today, I am immersed in my work", $0=$ Totally disagree, to $6=$ Totally agree, Bakker \& Oerlemans, 2019).

Finally, participants responded to an attention check question ${ }^{2}$, reported demographics and were debriefed.

\section{Results}

We conducted independent samples $t$-tests to examine the effect of meaning intervention as compared to the control condition. As predicted, the intervention boosted perceived work meaningfulness $t(224.29)=2.10, p=.04, d=0.28$ and elevated momentary work engagement, $t(225)=2.19, p=.03, d=0.29$. There was no significant difference between the intervention and the control condition with regards to searching for work meaning, $t(225)=-.37, p=.71, d=0.05(\text { Table } 1)^{3}$.

\footnotetext{
${ }^{2}$ Only two participants failed the attention check.

${ }^{3}$ When the analysis was conducted without the two participants, it did not change the pattern of results. There were no significant differences in searching for meaning between the conditions, $t(223)=-.36, p=.723, d=$
} 


\section{Meaning Interventions and Its Effect on Momentary Work Engagement Through Work}

\section{Meaningfulness}

We tested for a possible sequential mediation effect with a bias-corrected bootstrapping procedure (10,000 samples; PROCESS Model 4; Hayes, 2018). We used the experimental manipulation as IV (dummy coded, with the control condition $=0$ ), momentary work engagement as the DV, and the level of work meaningfulness as putative mediator. The variables were standardized prior to including in the analysis. The total effect of the intervention on momentary work engagement was significant, $b^{*}=.14, t(225)=2.19, p=.03$, $C I[0.01,0.27]$. The intervention predicted work meaningfulness, $b^{*}=.14, t(225)=2.08, p=$ $.04, C I[0.01,0.27]$. When the mediator was entered alongside the independent variable as predictor of momentary work engagement, the results showed that the intervention no longer predicted momentary work engagement, $b^{*}=.05, t(224)=1.01, p=.31, C I[-0.05,0.14]$. Work meaningfulness was significantly related to momentary work engagement, $b^{*}=.70$, $t(224)=14.75, p<.001, C I[0.61,0.80]$. Total partially standardized indirect effects were significant, $a b=.10$, boot $S E=0.05,95 \%$ boot $C I[0.01,0.18]$ suggesting that work meaningfulness was a significant mediator between the intervention and momentary work engagement (Figure 1). These results suggest that briefly contemplating the meaningfulness of one's work increases momentary work engagement, plausibly as a result of the increased work meaningfulness that this reflective task imbues.

We additionally summarized the responses provided by the participants and categorized their 107 replies to the meaning intervention condition. We categorized them into self-oriented sources of work meaningfulness, other-oriented sources of work meaningfulness or having both sources of work meaningfulness. Almost $21 \%$ of all the replies were characterized as "self-oriented", $48 \%$ as "other-oriented" and $30 \%$ as entailing both self-

0.05 , work meaningfulness was higher in the intervention condition, $t(221.81)=2.22, p=.027, d=0.29$ and so was momentary work engagement, $t(223)=2.37, p=.019, d=0.31$. 
oriented and other-oriented sources of meaningful work. There were two replies (2\%) that did not fit either of the categories (e.g., "I feel, work is nothing but the duty. To have a meaningful life one should have do the duty by means of work. It may vary from person to person. Some may do the charity as work and some may do a job for the private farm.”). The examples of the replies provided by the participants can be found in Table 2 .

\section{Study 2}

Next, we tested if an intervention aimed at emphasizing the benefits of one's work for the self or others (vs. control) enhanced momentary work engagement through changes in work meaningfulness. The study was pre-registered at https://aspredicted.org/blind.php? $\mathrm{x}=\mathrm{sk} 2 \mathrm{f} 5 \mathrm{x}$ and the reported data is available at https://osf.io/zbf4n/?view_only=3cd8e50959fb4975b2ec90f222207359. The research was approved by the Ethics Committee at the first author's university (Approval number 02/P/05/2020).

\section{Participants and Design}

Sample size was determined assuming an effect size of $f=.07,(\alpha=.05)$ with a power of $(1-\beta)=.95$. We aimed at recruiting at least 250 participants accordingly. Two hundred and fifty-four MTurk workers who were then employed or were business owners (108 women, 141 men, 5 undisclosed; age ranged from 21 to $71, M_{\text {age }}=38.60 S D_{\text {age }}=11.27$ ) took part in this online study in exchange for $0.80 \$$. Only one per cent of participants worked up to one year in total, $22 \%$ worked between 1 to 5 years, $24 \%$ had from 5 to 10 years of working experience and the remaining $53 \%$ of participants worked more than 10 years. When it comes to highest education attained, 5\% of participants had high school education or less, $21 \%$ had some college or an associate degree, $48 \%$ had a Bachelor's degree and the remaining $24 \%$ had at least Master's degree. Participants were randomly assigned to one of three conditions (self- 
vs. other-oriented meaning interventions vs. control) of a between-subjects design. No cases were dropped.

\section{Procedure and Materials}

Participants were randomly assigned to either one of the intervention conditions or the control condition. Participants in the self-oriented meaning condition read: "How does your work allow you to advance in your career? Think for a moment about this, and then write down three keywords that capture how your work allows you to advance your career." After providing the three keywords participants were asked to explain, in detail (i.e., in at least three sentences) how their work allowed them to advance in their career. In the other-oriented meaning condition participants were asked to write about how their work served a greater good. ${ }^{4}$ Participants in the control condition wrote about the equipment they used at work.

Participants then indicated how meaningful their work was with three items: "The work I do is very important to me"; "My job activities are personally meaningful to me" and "The work I do is meaningful to me" along with a response scale ranging from $1=$ Strongly disagree, to $5=$ Strongly agree $(\alpha=.93$, Spreitzer, 1995). Next, participants completed the three-item Momentary Work Engagement Scale. We adapted this measure to reflect their current situation: "The following statements are about how you feel at work today. Please read each statement carefully and decide if you feel this way about your job today. If you don't have this feeling, mark the ' 0 ' (zero) in the space after the statement. If you have this feeling, indicate how strongly you feel it by marking the number (from 1 to 6 ) that best describes how much you feel that way." ( $\alpha=.91$, "Today, I feel bursting with energy at my job"; “Today, my job inspires me"; "Today, I am immersed in my work", 0 = Totally disagree, to $6=$ Totally agree; Bakker \& Oerlemans, 2019).

\footnotetext{
${ }^{4}$ Results of an additional Study S1 $(N=260)$ presented in the Supplementary Materials showed that focus on 'serving greater good' and 'personal career' are related to other-oriented and self-oriented benefits, respectively. The study showed that focusing on the benefits of others during the meaning intervention affected momentary work engagement and work meaningfulness mediated this relationship.
} 
Participants then answered a manipulation check question: "At the beginning of this survey, in the open-ended question we asked you to describe your work in a few sentences. Now, please think about what you wrote and tell us: Did you describe your work as beneficial to you or to other people? If so, to what extent?" (1 = I definitely focused on how my work brings benefits to me, to $7=$ I definitely focused on how my work brings benefits to other people). Finally, participants reported demographics and were debriefed.

\section{Results}

\section{Manipulation Check}

We conducted an analysis of variance (ANOVA) and found that the conditions differed significantly in terms of participants' declared focus on describing the benefits for others versus oneself in the writing task, $F(2,249)=25.42, p<.001, \eta_{p}{ }^{2}=.17$. As intended, participants in the other-oriented condition declared reporting more about benefits of their work for others compared to those in the self-oriented condition $(p<.001)$, and compared to the control condition $(p<.001)$. Participants in the self-oriented condition reported describing more benefits for the self than those in the control condition at a trend level $(p=.06$, Table 3$)$. Comparison of the means was conducted with Bonferroni correction.

\section{Work Meaningfulness, Momentary Work Engagement and Meaning Interventions}

We next conducted ANOVAs to test if the experimental manipulation influenced perceived work meaningfulness and momentary work engagement. A first ANOVA on work meaningfulness showed differences between the conditions only at a trend level, $F(2,251)=$ $2.49, p=.09, \eta_{p}{ }^{2}=.02$. We conducted a mean comparison with Bonferroni correction. There were neither significant differences in perceived work meaningfulness between the selforiented and the control conditions $(p=.96)$, nor between self-oriented and other-oriented conditions $(p=.58)$. There was a difference in work meaningfulness between the control condition and the other-oriented condition at a trend level $(p=.08)$. There were no significant 
differences in momentary work engagement between the conditions, $F(2,251)=1.37, p=$ $.26, \eta_{p}^{2}=.01$.

We tested for a possible indirect effect using sampling with replacement, with a biascorrected bootstrapping procedure (10,000 samples; PROCESS Model 4; Hayes, 2018). We used experimental manipulation as IV (dummy coded, with the control condition as the reference point), momentary work engagement as the DV and the level of work meaningfulness as a possible mediator. The variables were standardized prior to including in the analysis. An omnibus test of total effect of the intervention on momentary work engagement was not significant, $F(2,251)=1.37, p=.26, R^{2}=.01$. Additionally, the relative total effects were also not significant (other-oriented, $p=.10$; self-oriented, $p=.43$ ). Relative to the control, the other-oriented condition increased work meaningfulness $b^{*}=.35, t(251)=$ $2.22, p=.03$. The self-oriented condition, relative to control, did not predict work meaningfulness significantly, $b^{*}=.15, t(251)=1.00, p=.32$. Work meaningfulness was a significant predictor of momentary work engagement, $b^{*}=.70, t(250)=15.50, p<.001$. Critically, the partially standardized relative indirect effect for the other-oriented condition (vs. the control) was statistically significant, $a b=0.25$, bootSE $=0.11,95 \%$ boot $C I[0.03$, 0.46]. There was no significant indirect effect for the self-oriented condition (vs. the control), $a_{2} b_{2}=0.10$, bootSE $=0.12,95 \%$ boot $C I[-0.13,0.34]$ (Figure 2$)$. This suggests that work meaningfulness played the role of a mediator only in case of the other-oriented meaning intervention ${ }^{5}$.

We also examined the content of the replies provided by the participants. One of the authors coded the replies using a $1=$ benefiting the self, $4=$ neither self, nor other, to $7=$ benefiting others, blind to condition. A one-way ANOVA showed that participants wrote

\footnotetext{
${ }^{5}$ Results of Study S1 described in the Supplementary Materials showed a similar pattern of results in that focusing on the benefits of others during the meaning intervention affected momentary work engagement and work meaningfulness mediated this relationship.
} 
more on why their job brings benefits to others in the other-oriented intervention condition $(M$ $=5.22, S D=1.50)$, than in the control condition $(M=4.00, S D=0.46)$; they also wrote more on personal benefits in the self-oriented intervention condition $(M=2.58, S D=1.21), F(251)$ $=114.90, p<.001, \eta_{p}{ }^{2}=.48$. Comparison of means with Bonferroni correction indicated that the differences were significant between all the means at $p<.001$. In addition, we also correlated coder's evaluation of self- vs other- benefits in the replies of participants with descriptions of the focus on self- vs other- benefits as stated by the participants. The results showed that the two variables were positively correlated, $r(254)=.38, p<.001$, suggesting that self-reports and coded responses converged to some degree. Example statements coming from the three conditions are presented in Table 4.

\section{Discussion}

The results of Study 1 indicated that a short, online intervention can successfully boost work meaningfulness and momentary work engagement. The results of Study 2 partially confirmed the hypothesis on the effect of self- and other-oriented meaning interventions on work meaningfulness and work engagement: an other-oriented meaning intervention increased work meaningfulness. We found that even when participants were asked to focus on self-oriented goals, which were potential sources of meaningful work, this did not result in higher work meaningfulness and work engagement. This suggests that it is not just a regular focus on self-benefit that prevents increases in work meaningfulness (or work engagement), but also a focus on self-benefits that were previously identified as a source of work meaningfulness (i.e., "personal growth and entertainment”, Allan et al., 2014). Work meaningfulness was related to momentary work engagement, which corroborates previous findings that linked trait-like work engagement with work meaningfulness (e.g., May et al., 2004). 
The present research suggests that a short online intervention that encourages individuals to focus on how one's work benefits others can increase momentary work engagement through changes in work meaningfulness. These findings have tentative practical implications: they show that even brief and relatively simple interventions can lead to an outcome, namely work engagement that is beneficial both for an individual and an organization. In practical terms, reframing one's job tasks to highlight how they serve others could be a part of regular encounters between supervisors and employees.

There is both a theoretical and an empirical basis for the links between each element of the model we tested. Namely, focus on others is related to higher work meaningfulness (e.g., Allan et al., 2018) and work meaningfulness is related to work engagement (e.g., Landells \& Albrecht, 2019). Drawing on the JCM (Hackman \& Oldham, 1976), this research is the first that joins these two paths and tests a causal model that focuses on one of the antecedents of work meaningfulness and work engagement as its consequences. We hope that, in doing so, our research helps advance both theoretical and experimental work on psychological functioning of individuals in their workplace.

We did not test what effect a simultaneous focus on benefits of others and the self could have on work meaningfulness and work engagement. On the one hand, the focus on the self-benefits could cancel out the positive effect that focus on others has on work meaningfulness, in line with the results of our study showing that a self-oriented intervention, did not increment work meaningfulness. However, we cannot rule out a synergistic effect that such an intervention could have. Although people differ in social value orientation and some individuals tend to value more focus on others than on the self (Murphy et al., 2011), research shows that individuals' preferences tend to entail a composite of social utility (another's benefits) and nonsocial utility (one's own benefits) (Loewenstein et al., 1989; Messick \& 
Sentis, 1985). This seems like an exciting line of research that could be pursued in future studies and could advance the causal model that we tested in the present research.

Work meaningfulness and work engagement are theoretically separate constructs, yet studies (including the present research) show that the relationship between the constructs is very strong (for a meta-analysis see Allan et al. 2019). Although this falls somewhat outside of the scope of this article, we note that such a strong relationship does pose a question of the type of relationship that there is between the variables. Is work meaningfulness a necessary condition to elicit work engagement? If so, how does it relate to other antecedents of work engagement like job control and organization-based self-esteem (Mauno et al., 2007). More research is needed to establish the type of relationship there is between work engagement and work meaningfulness.

It is important to recognize that, while our studies suggest that work meaningfulness is to a degree malleable, there are likely systematic factors that restrict people's ability to obtain high levels of work meaningfulness. For example, Hirschi (2012) found that work meaningfulness was positively correlated with occupational self-efficacy, suggesting that the work meaningfulness may be more readily available to those who believe themselves able to control their activities. Furthermore, Allan and colleagues (2014) found that employees from 'higher' social class performed jobs they considered more meaningful. This association was statistically mediated by volition and lower financial constraints, suggesting that a reason why those from a 'lower' social class background had jobs they found less meaningful may be due to less perceived opportunities to make occupational decisions alongside a more restrictive financial situation.

In the presented studies we did not measure many demographics that would be worth to control for in future studies. This would allow to test if implications of the meaning interventions differ depending on specific populations that vary in race or ethnicity. We 
further acknowledge that the effects we observed were rather small. However, such short online interventions that can boost momentary work engagement through changes in work meaningfulness are cost-effective, immediate and easily scalable. Accordingly, they can potentially be beneficial to many people in a relatively simple manner. They also provide promising grounds for future, more complex interventions. These could either entail repeating the same instruction over a period of time or use a more intense and engaging task that boosts work meaningfulness (e.g., Fletcher \& Schofield, 2019). Hulshof (2020) showed that taking actions to change one's job activities in a desired way was related to job performance through work meaningfulness and work engagement. It would be interesting to see if short online meaning interventions can increase performance at work (e.g., at a task level) through work meaningfulness and work engagement.

Researchers argue that there is still not enough research that points to which work meaningfulness or work engagement enhancing interventions are most effective (Bailey et al., 2018; Knight et al., 2017). We found that a short, online meaning intervention is effective in bolstering work meaningfulness and momentary work engagement. Additionally, it is above all an other-oriented meaning intervention that boosts momentary work engagement indirectly through changes in work meaningfulness. These findings indicate a new type of intervention that may be further explored in theory and practice. 


\section{References}

Adair, K. C., Rodriguez-Homs, L. G., Masoud, S., Mosca, P. J., \& Sexton, J. B. (2020). Gratitude at work: prospective cohort study of a web-based, single-exposure well-being Intervention for Health Care Workers. Journal of Medical Internet Research, 22, 5, e15562. doi.org/10.2196/15562

Allan, B. A., Autin, K. L., \& Duffy, R. D. (2014). Examining social class and work meaning within the Psychology of Working Framework. The Journal of Career Assessment, 22, 543-561. https://doi.org/10.1177/1069072713514811

Allan, B. A., Batz-Barbarich, C., Sterling, H. M., \& Tay, L. (2019). Outcomes of meaningful work: A meta-analysis. Journal of Management Studies, 56(3), 500-528. https://doi.org/10.1111/joms.12406

Allan, B.A., Duffy, R.D., \& Collison, B. (2018). Helping others increases meaningful work: Evidence from three experiments. Journal of Counseling Psychology, 65, 155-165. https://doi.org/10.1037/cou0000228

Andersson, G. (2018). Internet interventions: Past, present and future. Internet Interventions 6;12, 181-188. https://doi.org/10.1016/j.invent.2018.03.008.

Bailey, C., Yeoman, R., Madden, A., Thompson, M., \& Kerridge, G. (2018). A review of the empirical literature on meaningful work: Progress and research agenda. Human Resource Development Review, $\quad$ 83-113. https://doi.org/10.1177/1534484318804653

Bakker, A. B., \& Albrecht, S. (2018). Work engagement: current trends. Career Development International, 23, 1, 4-11. https://doi.org/10.1108/CDI-11-2017-0207

Bakker, A. B., \& Oerlemans, W. G. (2019). Daily job crafting and momentary work engagement: A self-determination and self-regulation perspective. Journal of Vocational Behavior, 112, 417-430. https://doi.org/10.1016/j.jvb.2018.12.005 
Bakker, A. B., \& Schaufeli, W. B. (2014). Work engagement. Organizational Behaviour: The Blackwell Encyclopedia of Management. West Sussex, UK: Wiley.

Breevaart, K., Bakker, A.B., Demerouti, E., \& Hetland, J. (2012). The measurement of state work engagement: A multilevel factor analytic study. European Journal of Psychological Assessment, 28, 4, 305-312. https://doi.org/10.1027/1015-5759/a000111

Cantarero, K., van Tilburg, W. A., \& Smoktunowicz, E. (2021). Affirming basic psychological needs promotes mental well-being during the COVID-19 outbreak. Social Psychological and Personality Science, $12, \quad 5, \quad 821-828$. https://doi.org/10.1177/1948550620942708

Davis, D. E., Choe, E., Meyers, J., Wade, N., Varjas, K., Gifford, A., Quinn, A., Hook, J. N., Van Tongeren, D. R., Griffin, B. J., \& Worthington, E. L., Jr. (2016). Thankful for the little things: A meta-analysis of gratitude interventions. Journal of Counseling Psychology, 63, 1, 20-31. https://doi.org/10.1037/cou0000107

Fletcher, L., \& Schofield, K. (2019). Facilitating meaningfulness in the workplace: a field intervention study. The International Journal of Human Resource Management, 1-29. https://doi.org/10.1080/09585192.2019.1624590

Hackman, J.R., \& Oldham, G.R. (1976). Motivation through the design of work: Test of a theory. Organizational Behavior and Human Performance, 16, 250-279. https://doi.org/10.1016/0030-5073(76)90016-7

Hakanen, J. J., \& Schaufeli, W. B. (2012). Do burnout and work engagement predict depressive symptoms and life satisfaction? A three-wave seven-year prospective study. Journal of Affective Disorders, 141, 415-424. https://doi.org/10.1016/j.jad.2012.02.043.

Hayes, A.F. (2017). Introduction to Mediation, Moderation, and Conditional Process Analysis. A Regression-Based Approach. $2^{\text {nd }}$ Edition. New York: The Guilford Press 
Hirschi, A. (2012). Callings and work engagement: moderated mediation model of work meaningfulness, occupational identity, and occupational self-efficacy. Journal of Counseling Psychology, 59, 3, 479. https://doi.org/10.1037/a0028949

Hulshof, I. L., Demerouti, E., \& Le Blanc, P. M. (2020). Day-level job crafting and serviceoriented task performance. Career Development International, 25, 4, 355-371. https://doi.org/10.1108/CDI-05-2019-0111

Humphrey, S. E., Nahrgang, J. D., \& Morgeson, F. P. (2007). Integrating motivational, social, and contextual work design features: A meta-analytic summary and theoretical extension of the work design literature. Journal of Applied Psychology, 92, 5, 13321356. https://doi.org/10.1037/0021-9010.92.5.1332

Knight, C., Patterson, M., \& Dawson, J. (2017). Building work engagement: A systematic review and meta-analysis investigating the effectiveness of work engagement interventions. Journal of Organizational Behavior, 38, 6, 792-812. https://doi.org/10.1002/job.2167

Landells, E. M., \& Albrecht, S. L. (2019). perceived organizational politics, engagement, and stress: The mediating influence of meaningful work. Frontiers in Psychology, 10, Article 1612. https://doi.org/10.3389/fpsyg .2019.01612

Lavy, S., \& Naama-Ghanayim, E. (2020).Why care about caring? Linking teachers' caring and sense of meaning at work with students' self-esteem, well-being, and school engagement. Teaching and Teacher Education, 91, Article 103046. https://doi.org/10.1016/j.tate.2020.103046

Loewenstein, G. F., Thompson, L., \& Bazerman, M. H., 1989. Social utility and decision making in interpersonal contexts. Journal of Personality and Social Psychology, 57, 3, 426-441. https://doi.org/10.1037/0022-3514.57.3.426 
Lysova, E.I., Allan, B.A., Dik, B.J., Duffy, R.D., \& Steger, M.F. (2019). Fostering meaningful work in organizations: A multi-level review and integration. Journal of Vocational Behavior, 110, 374-389. https://doi.org/10.1016/j.jvb.2018.07.004

May, D. R., Gilson, R. L., \& Harter, L. M. (2004). The psychological conditions of meaningfulness, safety and availability and the engagement of the human spirit at work. Journal of Occupational and Organizational Psychology, 77, 11-37. https://doi.org/10.1348/096317904322915892

Mauno, S., Kinnunen, U., \& Ruokolainen, M. (2007). Job demands and resources as antecedents of work engagement: A longitudinal study. Journal of Vocational Behavior, 70(1), 149-171. https://doi.org/10 .1016/j.jvb.2006.09.002

Messick, D. M., \& Sentis, K. P., 1985. Estimating social and nonsocial utility functions from ordinal data. European Journal of Social Psychology, 15, 389-399. https://doi.org/10.1002/ejsp.2420150403

Murphy, R. O., Ackermann, K. A., \& Handgraaf, M. (2011). Measuring social value orientation. Judgment and Decision Making, 6, 8, 771-781.

Rosso, B. D., Dekas, K. H., \& Wrzesniewski, A. (2010). On the meaning of work: A theoretical integration and review. Research in Organizational Behavior, 30, 91-127. https://doi.org/10.1016/j.riob.2010.09.001

Schaufeli, W. B., \& Bakker, A. B. (2014). Defining and measuring work engagement: Bringing clarity to the concept. In: A. B. Bakker \& M. P. Leiter (Eds.), Work engagement: A handbook of essential theory and research (pp. 10-24). New York: Psychology Press.

Schaufeli, W. B., Salanova, M., González-Romá, V., \& Bakker, A. B. (2002). The measurement of engagement and burnout: A two sample confirmatory factor analytic approach. Journal of Happiness studies, 3(1), 71-92. https://doi.org/10.1023/A:1015630930326 
Schaufeli, W. B., Shimazu, A., Hakanen, J., Salanova, M., \& De Witte, H. (2017). An ultrashort measure for work engagement: The UWES-3 validation across five countries. European Journal of Psychological Assessment 35, 4, 577-591. https://doi.org/10.1027/1015-5759/a000430

Sonnentag, S., Dormann, C.,\& Demerouti, E. (2010). Not all days are equal: The concept of state work engagement. In M. P. Leiter \& A. B. Bakker (Eds.), Work engagement: A handbook of essential theory and research (pp. 25-30). New York: Psychology Press.

Spreitzer, G. (1995). Psychological empowerment in the workplace: Dimensions, measurement and validation. Academy of Management Journal, 38(5), 1442-1465. https://doi.org/10.5465/256865

Steger, M. (2017). Creating meaning and purpose at work. In: L.G. Oades, M.F. Steger, A. Delle Fave, \& J. Passmore (Eds) The Wiley Blackwell Handbook of the Psychology of Positivity and Strenghts-Based Approaches at Work (pp. 60-81). New Jersey: WileyBlackwell. https://doi.org/10.1002/9781118977620.ch5

Stein, M. K., Wagner, E. L., Tierney, P., Newell, S., \& Galliers, R. D. (2019). Datification and the Pursuit of Meaningfulness in Work. Journal of Management Studies, 56, 3, 685717. https://doi.org/10.1111/joms.12409

Wang, K., Goldenberg, A., Dorison, C. A., Miller, J. K., Uusberg, A., Lerner, J. S., ... \& Isager, P. M. (2021). A multi-country test of brief reappraisal interventions on emotions during the COVID-19 pandemic. Nature Human Behaviour, 5(8), 1089-1110. https://doi.org/10.1038/s41562- 021-01173-x 


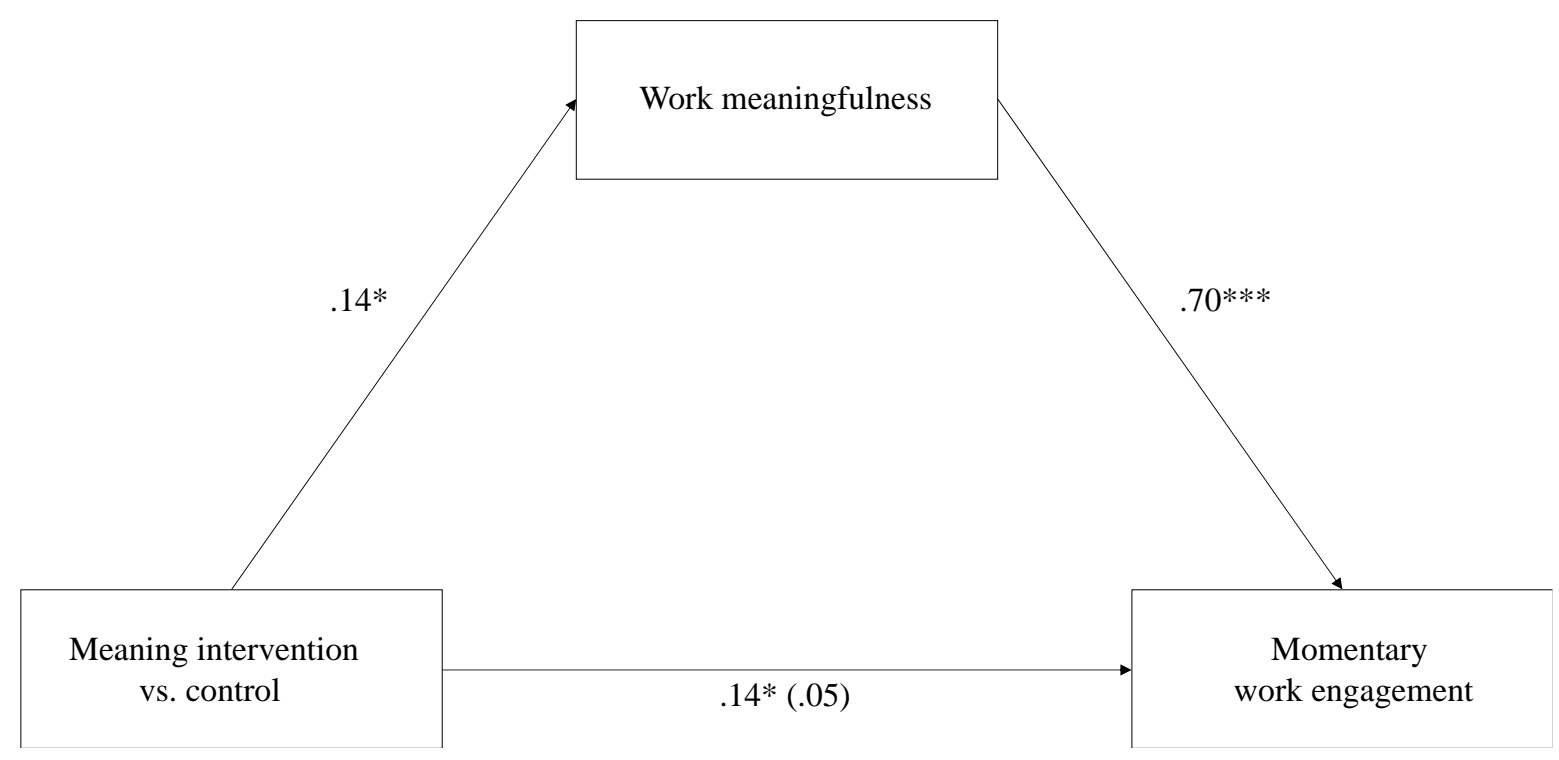

Figure 1. Mediation Model Testing That Work Meaningfulness Mediates the Effect of Meaning Intervention on Momentary Work Engagement, $* p<.05, * * * p<.001$.

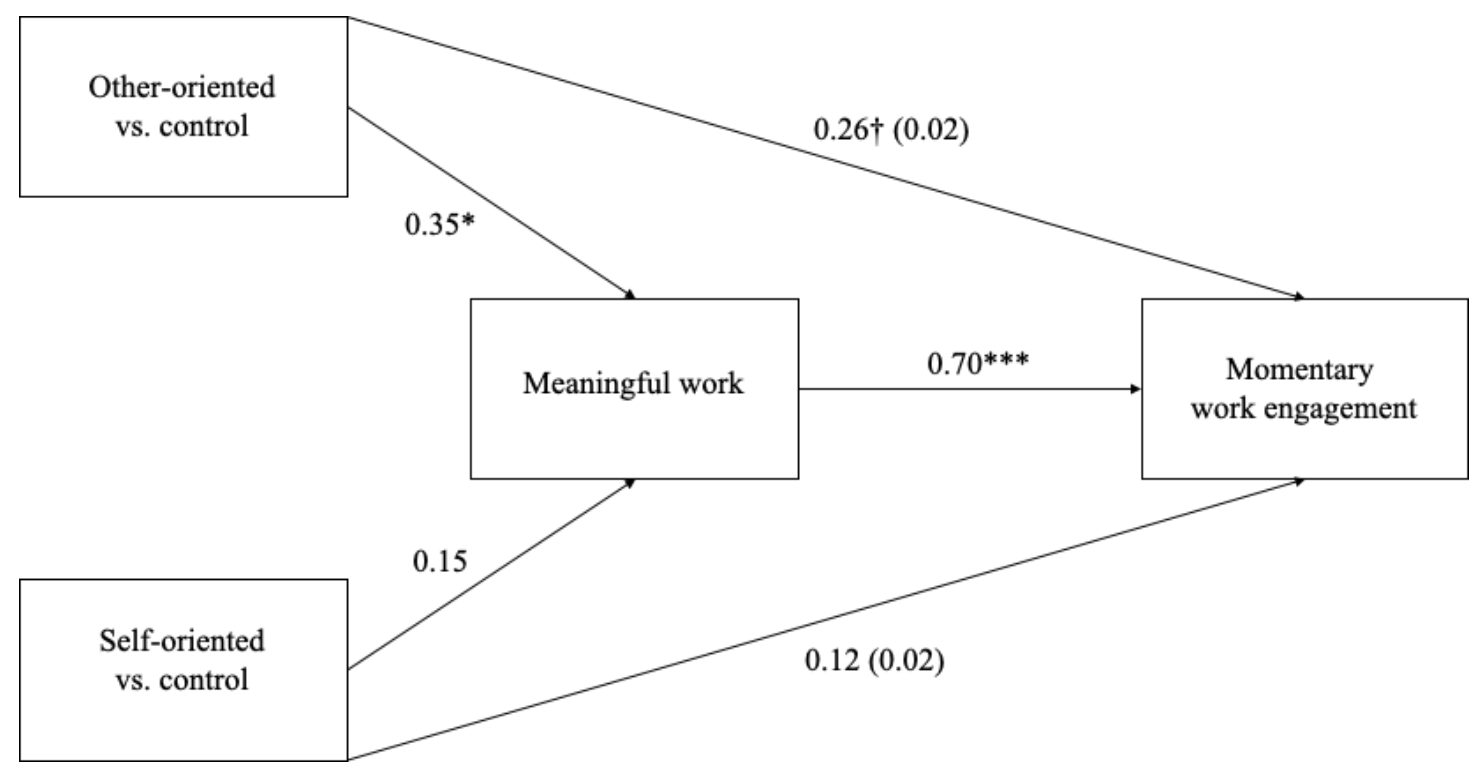

Figure 2. Mediation Model Testing That Work Meaningfulness Mediates the Effect of Two Types of Meaning Intervention on Momentary Work Engagement, $\dagger p=.10, * p<.05$, ** $p<$ $.01, * * * p<.001$. 


\section{Table 1}

Mean differences between the meaning intervention and the control condition in searching for work meaning, work meaningfulness and momentary work engagement, Study 1.

\begin{tabular}{|c|c|c|c|c|}
\hline \multirow{3}{*}{ Variable } & \multicolumn{4}{|c|}{ Meaning } \\
\hline & \multicolumn{2}{|c|}{ Intervention } & \multicolumn{2}{|c|}{ Control } \\
\hline & $M$ & $S D$ & $M$ & $S D$ \\
\hline Searching for work meaning & 3.34 & 1.02 & 3.39 & 0.98 \\
\hline Work meaningfulness & 3.95 & 1.05 & 3.63 & 1.25 \\
\hline Momentary work engagement & 3.59 & 1.58 & 3.13 & 1.55 \\
\hline
\end{tabular}


Table 2

\section{Example replies of participants provided in the meaning intervention condition, Study 1.}

Self-benefit
My work challenges me to be more
creative. Finishing the projects I
work on is very satisfying. Because
of the creative nature of my work I
find it to be very fun at times.

My work is so much fulfiling. I am so comfortable working in my organization and I always look forward to my work day. I get treated so well by my employer and he is very supportive.

I get decent flexibility, I work with easy going people, the job pays well for the responsibilities.

What I do is in the luxury sector so what we deal with is very fun and there are a lot of opportunities. Most people probably will not travel as much in their entire lives as much as I did last year. Because of that I think the people who are attracted to this industry are very great people as well.

My work is meaningful to me because it allows me to support myself. I am able to successfully manage my finances and lifestyle. I'm also able to save for the future, through the income earned from my work.

Other-benefit Both self- and other- benefit

My work is meaningful due to the fact that I teach adolescents conversational English online. I help expose them to a language that will give them personal and professional opportunities. I do this by making English learning fun and inspiring.

In my job I assist researchers at a university with applying for research grants. If they are successfully awarded one of those grants, it enables them to perform medical research that may lead to the new treatments and therapies for various diseases. This research is for the betterment of our community both global and local

I help make an impact in my community. I help in the healthcare and healing of patients. I help the company grow and better itself.

I help out individuals who have intellectual and autistic disabilities. I oversee their placement in a shared living home with a 'foster' family. The family incorporates the individual into their home and family. I provide support, education, advocacy to the individual and to the family.

I work for local government proudly serving my community. I work at the taxes department in an information capacity. I assist community members in paying their taxes and make them feel at ease about the whole process.
My work is meaningful because I am able to help others. It is satisfying because I am able to do what I like. I am able to be informative on new products and updates.

My work is meaningful because it can help others to learn. It is also meaningful because it helps pay down my debt. My work is meaningful as it help me acquire new knowledge.

We provide funding to those in need. It is a secure position. My job offers me flexibility in schedule which is meaningful to my personal life

I am earning money through my work which helps take care of my needs. The work I do is effected in making others lives better. I and I actually enjoy the work I do.

My work affords me the opportunity to support my family in meaningful ways. I am also providing a service for my customers which is rewarding. All of this helps to raise my self esteem. 
Table 3

Difference in Reported Focus on Others, Work Meaningfulness and Momentary Work Engagement in the Intervention vs. Control Condition, Study 2.

\begin{tabular}{|c|c|c|c|c|c|}
\hline \multirow[b]{2}{*}{ Variable } & Other-oriented & \multicolumn{2}{|c|}{$\underline{\text { Self-oriented }}$} & \multicolumn{2}{|c|}{$\underline{\text { Control }}$} \\
\hline & $S D$ & $M$ & $S D$ & $M$ & $S D$ \\
\hline Focus on others & 6.651 .74 & 4.34 & 2.54 & 5.13 & 2.09 \\
\hline Work meaningfulness & 4.180 .77 & 3.99 & 1.02 & 3.84 & 1.15 \\
\hline $\begin{array}{l}\text { Momentary work } \\
\text { engagement }\end{array}$ & 4.001 .52 & 3.78 & 1.57 & 3.58 & 1.74 \\
\hline
\end{tabular}


Table 4

Example replies of participants provided in the three experimental conditions (other-oriented, self-oriented meaning intervention, control), Study 2.

\begin{tabular}{|c|c|c|}
\hline Other & Control & Self \\
\hline $\begin{array}{l}\text { I feel like my work serves a greater } \\
\text { good by providing a service to } \\
\text { people, who then serve others more } \\
\text { directly. I am a source of knowledge } \\
\text { and information, and I have been } \\
\text { told many times that I have saved } \\
\text { someone time or worry by getting } \\
\text { what they need sorted for them. I } \\
\text { feel like my role allows me to have a } \\
\text { small impact on a large number of }\end{array}$ & $\begin{array}{l}\text { I work in photo post-production. I } \\
\text { use the PC all day to edit images. I } \\
\text { also use the pc and the } \\
\text { router/internet to access our site and } \\
\text { upload/deliver images to clients. }\end{array}$ & $\begin{array}{l}\text { In my personal field of work, I am } \\
\text { always learning something new in } \\
\text { order to help advance my career. I } \\
\text { work in a very empowering } \\
\text { workplace where my opinion is } \\
\text { actually valued! Being able to } \\
\text { express my opinion so freely and } \\
\text { being able o learn new things will } \\
\text { only help further my career path into } \\
\text { the hospitality industry. }\end{array}$ \\
\hline
\end{tabular}

I work in education. Hopefully I assist young people in gaining knowledge that will help them in their future. With knowledge these students will go out and become good citizens.

I'm a music producer and to be honest, I didn't/don't think music matters much to a society like the one we have right now. I expressed this to my cousin, a brilliant $\mathrm{PhD}$ of psychology, and he said he thinks people underestimate the impact they have on others. He may be right; soon after that, I was contacted by someone who told me that my music "helped him through a hard time."

When people get older they need help. Instead of having to go to a nursing home, they would be happier if they could stay in their own home . I assist them with chores and errands that they need so they can stay home longer.

My job serves the greater good because I teach young minds and help them towards success. I help them learn about the human body, how to be healthy, and how to exercise efficiently.
All of my work is done on the computer. I use a computer with dual monitors so that I can view documents on one screen and input data on the other screen. I also use a keyboard and mouse to get my work done.

I mainly use a forklift at work for unloading our trucks, after i use the electric pallet jack to sort and the freight in the warehouse. the toe motor we use to sort pallets we store outside

On my desk I have a keyboard attached to a computer. I type into the keyboard and use the computer for at least 6 hours a day. About 20 times a day I visit the copier, there I am able to make copies and augment my work done at the computer.

In my job there is physical labor. This labor requires tools and safety gear to perform. We also need to use our phones to communicate.
Work allows me to advance in my career by gaining experience for future opportunities. As well as allowing me to build the relationships and soft skills that are required to succeed in a business function.

My work is my career. I'm a physicist. My job allows me to advance my career. I'm a professor. In exchange for teaching about physics, I get to conduct research, publish the results, and collaborate with colleagues. I also get paid a bit.

my career enhances my knowledge in my field it gives more pleasant and brillian idea of working

In my work i have chance to learn new things every day. By learning new things i am getting more advanced in my career. 